\title{
Nocardiose pulmonar em portador de doença pulmonar obstrutiva crônica e bronquiectasias*
}

\author{
Pulmonary nocardiosis in a patient with chronic \\ obstructive pulmonary disease and bronchiectasis
Miguel Abidon Aidê', Silvia Soares Lourenço², Edson Marchiori ${ }^{3}$, Gláucia Zanetti ${ }^{4}$, Pedro Juan José Mondino ${ }^{5}$

\section{Resumo}

Relatamos o caso de um paciente com doença pulmonar obstrutiva crônica e bronquiectasias, em uso crônico de corticosteróides, que desenvolveu nocardiose pulmonar, sob a forma de múltiplos nódulos pulmonares escavados. Os sintomas principais foram a tosse produtiva com escarro purulento, febre e dispnéia A radiografia simples e a tomografia computadorizada do tórax mostravam nódulos em ambos os pulmões, alguns escavados. 0 exame direto de escarro e a cultura mostraram a presença de Nocardia spp. A paciente foi tratada com imipenem e cilastatina, com excelente resposta clínica.

Descritores: Doença pulmonar obstrutiva crônica; Nocardiose; Bronquiectasia.

\begin{abstract}
We report the case of a patient with chronic obstructive pulmonary disease and bronchiectasis, chronically using corticosteroids, who acquired pulmonary nocardiosis, which presented as multiple cavitated nodules. The principal symptoms were fever, dyspnea and productive cough with purulent sputum. Chest X-ray and computed tomography of the chest revealed nodules, some of which were cavitated, in both lungs. Sputum smear microscopy and culture revealed the presence of Nocardia spp. The patient was treated with imipenem and cilastatin, which produced an excellent clinical response.
\end{abstract}

Keywords: Pulmonary disease, chronic obstructive; Nocardia infections; Bronchiectasis.

\section{Introdução}

A nocardiose pulmonar é uma enfermidade pouco freqüente, causada por um actinomiceto Gram-positivo do gênero Nocardia. A estimativa de incidência nos EUA é de 500 a 1000 casos por ano. A transmissão ocorre por via inalatória e afeta mais comumente pacientes imunodeprimidos, devido a AIDS, neoplasias ou transplantes de rim e medula óssea, ocorrendo também em pacientes portadores de doença pulmonar obstrutiva crônica (DPOC) e bronquiectasias, notadamente naqueles que fazem uso crônico de corticosteróides.

0 objetivo deste trabalho é apresentar os achados de imagem-múltiplos nódulos pulmonares escavados-de um paciente com DPOC e bronquiectasias, em uso de corti- costeróide inalatório em dose máxima, cujo diagnóstico bacteriológico foi de nocardiose pulmonar.

\section{Relato de caso}

Mulher, branca, 89 anos, com DPOC e relato de bronquiectasias no lobo superior esquerdo há pelo menos 20 anos. 0 diagnóstico funcional de DOPC foi realizado pelo resultado da relação volume expiratório forçado no primeiro segundo/capacidade vital forçada de $41,2 \%$ após o uso de broncodilatador na prova de função pulmonar. Usava diariamente brometo de tiotrópio, $\beta 2$-agonista de longa duração, associado a corticosteróide inalatório desde setembro de

* Trabalho realizado na Universidade Federal Fluminense - UFF - Niterói (RJ) Brasil.

1. Coordenador do Curso de Especialização em Pneumologia da Universidade Federal Fluminense - UFF - Niterói (RJ) Brasil.

2. Médica Residente do Departamento de Radiologia da Universidade Federal Fluminense - UFF - Niterói (RJ) Brasil.

3. Chefe do Departamento de Radiologia da Universidade Federal Fluminense - UFF - Niterói (RJ) Brasil.

4. Professora de Clínica Médica da Faculdade de Medicina de Petrópolis, Petrópolis (RJ) Brasil.

5. Professor Assistente de Patologia da Universidade Federal Fluminense - UFF - Niterói (RJ) Brasil.

Endereço para correspondência: Miguel Abidon Aidê. Rua Uirapuru, 118, 1taipu, CEP 24355-100, Niterói, RJ, Brasil.

Tel 5521 2710-8740. E-mail: miguelaide@uol.com.br

Apoio financeiro: Nenhum.

Recebido para publicação em 17/12/2007. Aprovado, após revisão, em 26/3/2008. 
2004; nas exacerbações agudas, utilizava corticosteróide sistêmico associado a antibiótico de largo espectro. Há 5 dias iniciou quadro de tosse com secreção purulenta, febre de $38{ }^{\circ} \mathrm{C}$, sudorese noturna, prostração intensa, dispnéia e anorexia. Foi prescrito ciprofloxacina por 10 dias, sem melhora clínica, tendo sido internada por 10 dias pelo agravamento do quadro clínico. Nessa primeira internação, a radiografia de tórax mostrava espessamento de paredes brônquicas, pequenas opacidades mal definidas nos lobos superior e inferior direitos e atelectasia com bronquiectasias no lobo superior esquerdo. Foi isolada Klebsiella pneumoniae pela cultura do escarro, e prescrito ceftriaxone, piperacilina/tazobactan. Obteve alta com melhora da febre e da tosse. Em casa, houve recidiva dos sintomas com piora da dispnéia. Realizada radiografia do tórax no domicílio, com aparelho portátil, que mostrou imagens nodulares disseminadas nos pulmões, motivando uma segunda internação (Figura 1). Ao exame apresentava fácies de sofrimento; prostrada; hipocorada; taquipnéica (44 ciclos/min); taquicárdica (120 bpm); temperatura axilar, $37^{\circ} \mathrm{C}$; pressão arterial, 120/80 mmHg; e saturação periférica de oxigênio, 84\% em ar ambiente. Roncos em ambos os pulmões. 0 restante do exame não evidenciava alterações. Exames laboratoriais: 3.260.000 hemácias $/ \mathrm{mm}^{3}$; hematócrito, 28\%; hemoglobina, 9,6 g/dL; 11.130 leucócitos $/ \mathrm{mm}^{3}$; bastonetes, 5\%; segmentados, 64\%; eosinófilos, 0\%; linfócitos, $10 \%$; $\mathrm{pH}=7,4$; pressão parcial arterial de oxigênio, 68,7 mmHg; pressão parcial arterial de gás carbônico, 42,8 mmHg; saturação periférica de oxigênio, 93\%-com oxigênio a $3 \mathrm{~L} / \mathrm{min}$ sob cateter nasal; uréia, 44,3 mg/dL; creatinina, $1,26 \mathrm{mg} / \mathrm{dL}$; sódio, $135 \mathrm{mEq} / \mathrm{L}$; e potássio, $5,4 \mathrm{mEq} / \mathrm{L}$. Teste de função hepática, coagulograma, ecocardiograma e ultrassonografia pélvica estavam normais. Hemocultura e sorologia para HIV foram negativos.

Foi realizada tomografia computadorizada (TC) do tórax, que confirmou a presença dos nódulos com tamanhos variados, sendo alguns escavados (Figura 2). Três amostras seguidas de escarro com pesquisa de bacilos álcool-ácido resistentes e fungos (coloração pela prata) foram negativas. A bacterioscopia (Gram) mostrou a presença de bactérias filamentosas nas três amostras colhidas de escarro, fortemente sugestivas de Nocardia spp., confirmada pela coloração de Ziehl- Neelsen, mostrando a característica resistência parcial à solução álcoolácido (Figura 3).

Inicialmente foi prescrita a associação sulfametoxazol e trimetoprima, sem resposta clínica. Foram então prescritas amicacina associada a Imipenem/cilastatina por 15 dias, com excelente resposta clínica e radiológica (Figura 1). Recebeu alta hospitalar com prescrição de sulfametoxazol e trimetoprima por mais 8 semanas.
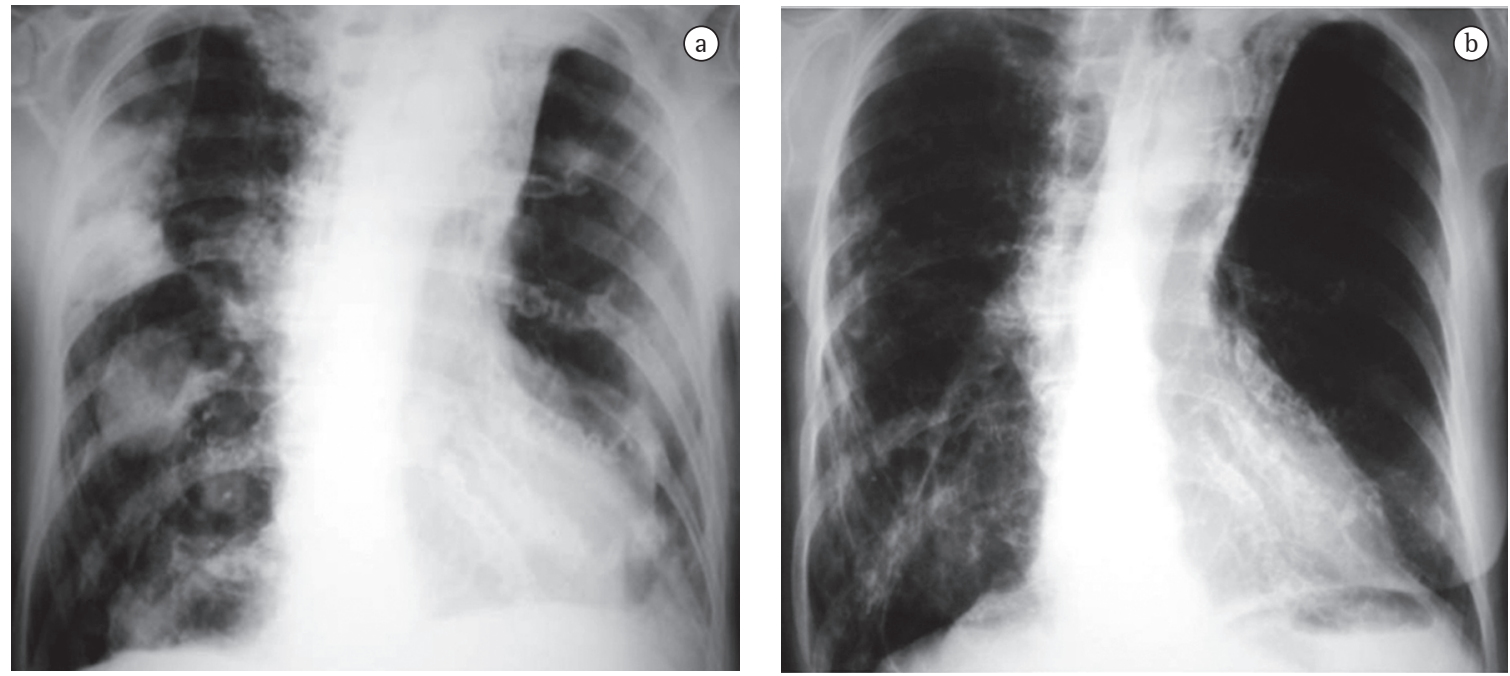

Figura 1 - Radiografias do tórax em incidência póstero-anterior. Em a) múltiplos nódulos de tamanhos variados, acometendo ambos os pulmões. Em b) exame de controle, feito 15 dias após, mostrando a resolução completa das lesões. 

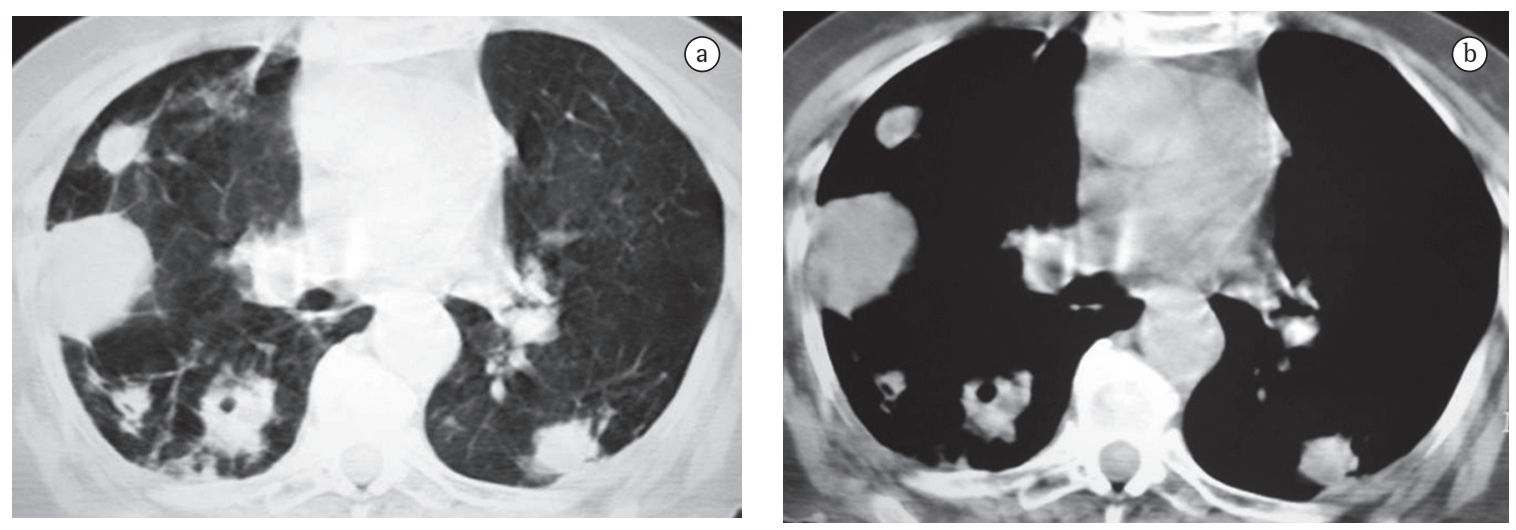

Figura 2 - Tomografias computadorizadas com janela para parênquima pulmonar a) e mediastino b), mostrando múltiplos nódulos pulmonares, de tamanhos variados, alguns deles escavados.

\section{Discussão}

A nocardiose pulmonar é uma infecção causada por bacilos aeróbios Gram-positivos do gênero Nocardia. Nocardia asteroides é a principal espécie envolvida, estando presente entre 70\% e 90\% dos casos. ${ }^{(1-6)}$ Nocardia spp. pode colonizar o trato respiratório sem causar sintomas ou anormalidades radiográficas. ${ }^{(1,3,5,7,8)}$

A transmissão ocorre por via inalatória e afeta principalmente pacientes com imunidade celular deprimida pelo HIV, neoplasias, transplantes, ou pelo uso crônico de corticosteróides, apesar de existirem

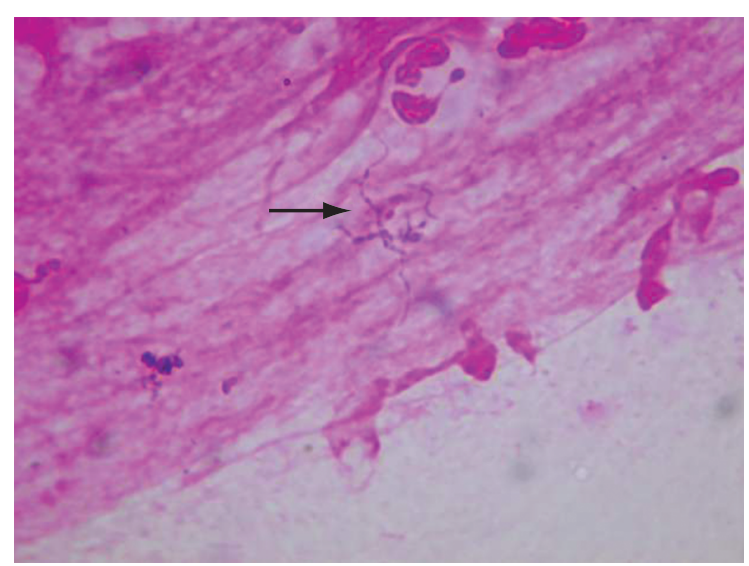

Figura 3 - Microscopia direta de esfregaço de escarro, corado pelo método de Gram. Em meio a muco e próxima a dois leucócitos polimorfonucleares, notamos a presença de bactéria filamentosa, ramificada, Gram-positiva, de coloração irregular, sugestiva de Nocardia spp.(seta preta cheia). relatos em pacientes previamente sadios. . $^{(1,3,5,6,9-9-11)}$ Em várias séries da literatura, correlacionando nocardiose com corticoterapia, foi demonstrado que a DPOC foi isoladamente a doença com a maior freqüência dessa associação..$^{(1,3)}$ Outra causa comum para este achado são as bronquiectasias. ${ }^{(5)}$

0 quadro clínico pulmonar pode apresentar evolução aguda, subaguda ou crônica, ${ }^{(3,5,9)}$ sendo os principais sintomas a dispnéia, tosse produtiva e febre. ${ }^{(2,8,9)}$ No caso relatado, a paciente apresentou um quadro de dispnéia e febre, além de tosse com secreção purulenta, sudorese noturna e prostração intensa, com posterior agravamento da dispnéia.

A apresentação radiológica torácica é inespecífica. Os achados radiológicos mais comuns são as consolidações e os grandes nódulos irregulares. Nódulos, massas escavadas, derrame pleural, pneumotórax, opacidades em vidro fosco e padrões intersticiais podem também ocorrer. ${ }^{(1,4,5,11)}$ Alguns estudos mostram que, em pacientes HIV positivos, existe um percentual maior de lesões escavadas. ${ }^{(8)} \mathrm{A}$ consolidação alveolar nos lobos superiores é muitas vezes confundida com tuberculose pulmonar. ${ }^{(6)}$ Embora as alterações vistas na TC sejam semelhantes às das radiografias convencionais, a TC é superior na demonstração da exata localização e extensão das lesões, assim como na diferenciação entre lesões pulmonares e pleurais. ${ }^{(5)}$ No caso relatado, a paciente apresentava imagens nodulares de tamanhos variados, disseminadas por ambos os pulmões, e algumas delas escavadas.

A confirmação do diagnóstico pode ser difícil, e depende da demonstração do microorganismo em amostras de escarro, lavado broncoalveolar ou do 
seu isolamento em cultura. ${ }^{(2,5,6)}$ Culturas de escarro são positivas em cerca de $90 \%$ dos pacientes, podendo chegar a 100\% quando o lavado broncoalveolar é realizado. ${ }^{(3)}$ É fundamental que o laboratório seja informado da suspeita de nocardiose. Por causa do crescimento lento da bactéria, o tempo de incubação da cultura deve ser prolongado por 20-30 dias, utilizando-se também concentrações e técnicas de descontaminação adequadas para a amostra. ${ }^{(2,3,6,9,11)} \mathrm{A}$ hemocultura raramente é positiva. ${ }^{(6)} A$ infecção muitas vezes é confundida com tuberculose, tanto pelo quadro clínico inespecífico, quanto pela característica álcool-ácido resistente do bacilo, que se cora positivamente pela técnica de Ziehl-Neelsen . (5,6,9) $^{-}$

Em conclusão, pacientes com DPOC e bronquiectasias, imunossuprimidos por uso crônico de corticosteróides, que apresentam consolidação alveolar ou nódulos pulmonares escavados, com ou sem derrame pleural, devem ser investigados quanto a possibilidade diagnóstica de nocardiose pulmonar.

\section{Referências}

1. Feigin DS. Nocardiosis of the lung: chest radiographic findings in 21 cases. Radiology. 1986;159(1):9-14.
2. Mari B, Montón C, Mariscal D, Luján M, Sala M, Domingo C. Pulmonary nocardiosis: clinical experience in ten cases. Respiration. 2001;68(4):382-8.

3. Menéndez R, Cordero PJ, Santos M, Gobernado M, Marco V. Pulmonary infection with Nocardia species: a report of 10 cases and review. Eur Respir J. 1997;10(7):1542-6.

4. Hwang JH, Koh WJ, Suh GY, Chung MP, Kim H, Kwon OJ, et al. Pulmonary nocardiosis with multiple cavitary nodules in a HIV-negative immunocompromised patient. Intern Med. 2004;43(9):852-4.

5. Silva AC, Martins EM, Marchiori E, Neto GT. Nocardiose pulmonar em paciente com síndrome da imunodeficiência adquirida: relato de caso. Radiol Bras. 2002;35(4):235-8.

6. Baldi BG, Santana AN, Takagaki TY. Pulmonary and cutaneous nocardiosis in a patient treated with corticosteroids. J Bras Pneumol. 2006;32(6):592-5.

7. Pifarré R, Teixidó B, Vilá M, Duran M, García JM, Morera J. Pulmonary nocardiosis as a cause of radiographic imaging of multiple pulmonary nodules [Article in Spanish]. Arch Bronconeumol. 2001;37(11):511-2.

8. Kramer MR, Uttamchandani RB. The radiographic appearance of pulmonary nocardiosis associated with AIDS. Chest. 1990;98(2):382-5.

9. Matulionyte R, Rohner P, Uçkay I, Lew D, Garbino J. Secular trends of nocardia infection over 15 years in a tertiary care hospital. J Clin Pathol. 2004;57(8):807-12.

10. Ferrer A, Llorenç V, Codina G, de Gracia-Roldán J. Nocardiosis and bronchiectasis. An uncommon association? [Article in Spanish] Enferm Infecc Microbiol Clin. 2005;23(2):62-6.

11. Díez-García MJ, Andreu AL, Chiner E. Bronchopneumonia due to Nocardia asteroides in a man with chronic obstructive pulmonary disease [Article in Spanish]. Arch Bronconeumol. 2005;41(11):642-3. 